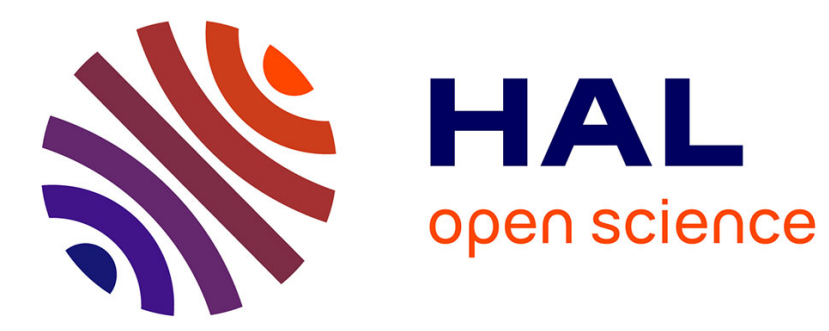

\title{
Experimental assessment of habitat preference and dispersal ability of soil springtails
}

Apolline Auclerc, Jean-François Ponge, Sébastien Barot, Florence Dubs

\section{To cite this version:}

Apolline Auclerc, Jean-François Ponge, Sébastien Barot, Florence Dubs. Experimental assessment of habitat preference and dispersal ability of soil springtails. Soil Biology and Biochemistry, 2009, 41 (8), pp.1596-1604. 10.1016/j.soilbio.2009.04.017 . hal-00494590

\section{HAL Id: hal-00494590 https://hal.science/hal-00494590}

Submitted on 23 Jun 2010

HAL is a multi-disciplinary open access archive for the deposit and dissemination of scientific research documents, whether they are published or not. The documents may come from teaching and research institutions in France or abroad, or from public or private research centers.
L'archive ouverte pluridisciplinaire HAL, est destinée au dépôt et à la diffusion de documents scientifiques de niveau recherche, publiés ou non, émanant des établissements d'enseignement et de recherche français ou étrangers, des laboratoires publics ou privés. 
1 Type of contribution: Regular paper

2

3 Date of preparation: 1 April 2009

4

Title: Experimental assessment of habitat preference and dispersal ability of soil springtails

6

7 Names of authors: A. Auclerc, J.F. Ponge*, S. Barot, F. Dubs

8

9 Complete postal addresses or affiliations:

10

11

A. Auclerc, J.F. Ponge: Muséum National d'Histoire Naturelle, CNRS UMR 7179, 4 avenue du Petit-

Chateau, 91800 Brunoy, France

13

14 S. Barot, F. Dubs: Institut de Recherche pour le Développement, UMR 7618 Bioemco, 32 avenue

Henri-Varagnat 93143 Bondy Cédex, France

16

Full telephone, Fax number and E-mail address of the corresponding author:

18

19

Tel. +33160479213

20

Fax +33160465009

21

E-mail: ponge@mnhn.fr 


\section{Abstract}

Beside biotic interactions, habitat preference and dispersal ability of species play a prominent role in the building of animal species assemblages. However, these traits are usually very poorly documented for soil organisms. A soil transfer experiment was designed to study habitat preference (including land-use and soil preference) and dispersal ability of soil springtail species living in a meadow and in an adjoining deciduous forest. The study was performed in the Morvan Regional Natural Park (Central France), using untreated or defaunated soil blocks, transferred to another landuse or replaced in their original land-use. Land-use preference was quantified in untreated and untransferred samples from meadow and forest. Dispersal ability was estimated from the time at which species colonized defaunated samples in their own habitat. Soil preference was estimated from the colonization rate of defaunated samples by comparing transferred and untransferred soil blocks. Results showed that in the community, $6 \%$ of species were land-use generalists, $30 \%$ were soil generalists and $36 \%$ recolonized defaunated soil blocks within a week. Land-use preference, soil preference and dispersal ability were largely independent components of species characteristics. Although our experiment dealt only with small-scale colonization, comparisons between species showed that the dispersal type based on anatomical features (legs, antenna, furcula, visual apparatus) does not allow predicting the dispersal ability of these species. Discrepancies between land-use preference and soil preference suggest that other habitat features must be relevant for Collembola, and that a trade-off exists between eco-physiological and biotic interactions (including food requirements).

Keywords: Collembola; forest; meadow; transfer experiment; habitat preference; land-use preference; soil preference; dispersal ability; morphological traits; response traits

\section{Introduction}


According to theories in community ecology (Drake, 1990; Hunter and Price, 1992; Clobert et al., 2001; Weiher and Keddy, 2001; Tews et al., 2004), the composition of species assemblages can be explained by three processes, the former two acting at the species level, the third one acting at the community level: (1) habitat preference, (2) dispersal, (3) biotic interactions (positive and negative).

66

These interconnected processes filter regional biodiversity, shaping species assemblages at the local level (Keddy, 1992; Zobel, 1997; Rajaniemi et al., 2006). Knowledge on habitat preference and dispersal ability is necessary to understand the distribution of species both at local and regional scales. Species belonging to the same community and thought to have similar or at least compatible ecological requirements may disperse at varying rates, and thus may respond differently to environmental change and heterogeneity (Ribera et al., 2001; Ponge et al., 2006). Indeed, dispersal ability and habitat preference constrain species capability to reach and occupy different parts of an ecosystem mosaics. Species with high dispersal ability are able to reach more easily all patches of the landscape and will respond to environmental and land-use change, while species with low dispersal ability might not reach some patches (depending on habitat connectivity) even those suitable in habitat requirements (Dunning et al., 1992; Andrén et al., 1997). Similarly, species with narrow habitat requirements are constrained to live in particular patches, which can also impede them to reach some patches (again depending on landscape structure).

Springtails are an integral part of healthy soils and play a critical role in ecosystem services such as dissemination and control of microbial communities (Rusek, 1998). They also influence litter decomposition by the control they have on microbial diversity (Hättenschwiler et al., 2005; Lavelle and Spain, 2005). Despite of their prominent role in structuring communities (see above), habitat preferences and dispersal abilities are still imperfectly known in this group. Moreover, documenting these traits could help understanding some features of Collembolan spatial distribution. For example, as many other soil invertebrates, they are poorly sensitive to habitat fragmentation at local scale $\left(1 \mathrm{~m}^{2}\right)$ 
(Rantalainen et al., 2008) even though they are sensitive to fragmentation at the landscape scale (1 $\mathrm{km}^{2}$ ) (Sousa et al., 2006) and they may suffer from land-use change due to poor active dispersal (Ponge et al., 2006) even if some species are known for their high passive dispersal ability (Van der Wurff et al. 2003). All these results show that (1) it is worth studying further the factors which shape Collembolan species assemblages in mosaics of land-uses and (2) documenting species characteristics such as dispersal and habitat preference would allow to better understand mechanisms hidden behind patterns of species distribution.

To do so, in situ transfer of soil blocks between a forest and a nearby meadow was performed to directly assess in the same experiment habitat preferences and dispersal abilities of all species of Collembola found. With this in situ experiment we could also identify whether species preference for meadow or forest is due to a preference for soil quality. As we documented different species characteristics, we could also test for significant correlations between them. For example we tested whether (1) land-use specialists (restricted to a given habitat) are also specialized in the soil type of their land-use, (2) habitat generalists have higher dispersal ability than habitat specialists.

\section{Materials and methods}

This field experiment was established in the Morvan Regional Natural Park (Central France) from December 2005 to June 2006 and was similar to the shorter-term and simpler experimental approach by Ponge et al. (2008).

\subsection{Study site}


The Morvan Regional Natural Park (Central France) is under submontane-atlantic climate with continental influence, with a mean annual rainfall of $1000 \mathrm{~mm}$, and a mean temperature of $9^{\circ} \mathrm{C}$. The parent rock is granite (Adolphe and Desmanèges-Lorenz, 1977). Soils are weakly to strongly acidic (Fédoroff \& Aurousseau, 1981), with a humus form sensu Brêthes et al. (1995) varying from Eumull to Dysmoder (Ponge et al., 2003).

\subsection{Experimental design}

On December 2005, 60 circular soil blocks $(15 \mathrm{~cm}$ diameter $\times 10 \mathrm{~cm}$ depth) were dug in both land-use plots along 10 evenly spaced transects ( $25 \mathrm{~m}$ between transects), with 6 blocks in each transect $(50 \mathrm{~cm}$ between blocks located in the same transect). Transects were perpendicular to the forest edge and started $10 \mathrm{~m}$ from it both in the forest and the meadow. Sixty soil blocks among 120 were dug ten days before start of the experiment then kept frozen to $-20^{\circ} \mathrm{C}$ in order to get rid of fauna, the other 60 being let undisturbed until start of the experiment.

while the remaining 15 untreated and 15 defaunated blocks were replaced in their original land-use plot. Meadow blocks were transferred with their original grass, without any further pre-treatment. In the same manner, forest blocks were transferred with their thick litter but with no ground vegetation (except some mosses). Taken together, eight treatments were implemented (Fig. 1), according to the 
initial presence or absence of fauna (W with fauna, $\mathrm{O}$ without fauna), land-use plots from which blocks have been taken ( $\mathrm{F}$ forest, $\mathrm{M}$ meadow), and land-use plots where blocks have been replaced ( $\mathrm{F}$ forest, $\mathrm{M}$ meadow). In each treatment (15 blocks), five blocks were sampled randomly one week after start of the experiment (December 2005), five others after 1 month (January 2006) and the remaining five after 6 months (June 2006). The following treatment codes were used in the experimental design: $\mathrm{OFF}=$ blocks without fauna taken in the forest and replaced in the forest; OFM = blocks without fauna taken in the forest and replaced in the meadow; OMM = blocks without fauna taken in the meadow and replaced in the meadow; OMF = blocks without fauna taken in the meadow and replaced in the forest; WFF = blocks with fauna taken in the forest and replaced in the forest; WFM = blocks with fauna taken in the forest and replaced in the meadow; WMM = blocks with fauna taken in the meadow and replaced in the meadow; $\mathrm{WMF}=$ blocks with fauna taken in the meadow and replaced in the forest.

Samples were immediately taken to the laboratory to be extracted over 10 days in a BerleseTullgren apparatus with a $15 \mathrm{~W}$ bulb lamp suspended over each sample. Extracted micro-arthropods were preserved in $95 \%$ ethyl alcohol until sorting and identification. Springtails were identified to species level under a binocular microscope $(50 \times)$ and a light microscope $(400 x)$ using keys by Gisin (1960), Zimdars and Dunger (1994), Potapow (2001), Thibaud et al. (2004) and Hopkin (2007).

\subsection{Characterization and statistical validation of classes of dispersal ability}

For each of the springtail species which were present in the 60 blocks replaced in their original environment (WFF, WMM, OFF, OMM), dispersal ability was defined by the time at which the species reappeared in the defaunated blocks (OFF, OMM). This allowed us to classify springtail species in four classes of dispersal ability, either in the forest or the meadow. Indeed, the dispersal 
148 ability of a species could well be different in the two land-use types (noted $\mathrm{F}$ in the forest and $\mathrm{M}$ in the

149 meadow): species for which the first individuals colonized defaunated blocks (1) within a week (F1 or 150 M1), (2) after a week and within a month (F2 or M2), (3) after a month and within six months (F3 or

151 M3), (4) species which did not colonize defaunated blocks after six months but were found in untreated blocks (F4 or M4). When species were never found in the land-use under investigation, we noted them M0 in the meadow and F0 in the forest.

To test the relevance of our four classes of dispersal ability, we tested the effect of the interaction between time and dispersal ability on the presence/absence of species using Generalized Linear Models (GLM) with binomial models for presence/absence of species (Pinheiro and Bates, 2000). We used OFF and OMM treatments for dispersal ability. All statistics were implemented using R software (Crawley, 2007).

\subsection{Characterization of species land-use preference and statistical validation of preference classes}

$A_{i j}=$ average abundance of species $i$ in blocks of habitat $j /$ average abundance of species $i$

$B_{i j}=$ number of blocks of habitat $j$ where species $i$ is present/number of blocks of habitat $j$ 
considered. For the calculation of the IndVal index, we only used untreated blocks that were replaced in their original land-use plot, i.e. WFF and WMM treatments.

For each species, we calculated forest and meadow IndVal indices using the 'duleg' function of the 'labdsv' package from R software (Ihaka and Gentleman, 1996). Then we classified the species in five groups according to their affinity for one or both land-uses: (1) forest specialists or strict-forest species (F), (2) forest-preferring species (FP), (3) meadow specialists or strict-meadow species (M), (4) meadow-preferring species (MP), (5) generalists (G).

To test the relevance of our classes of land-use preference, we tested the effect of the interaction between land-use preference and land-use category on the abundance and on the presence/absence of species using Generalized Linear Models (GLM) with approximate Poisson error for species abundance or binomial models for presence/absence of species (Pinheiro and Bates, 2000). We used WFF and WMM treatments to validate classes of land-use preference.

\subsection{Characterization of soil preference and statistical validation of preference classes}

To characterize the preference of species for soil types we compared defaunated or untreated soil blocks from a land-use with defaunated or untreated blocks transferred from the other land-use. For each species we run a Generalised Linear Model with approximate Poisson error to test for the effect of block transfer on species abundances. When this test was significant, the block type in which the species was the more abundant was considered as the preferred soil of the species. For strict forest, forest-preferring and generalist species, we used OFF-OMF and WFF-WMF treatments and for strict meadow, meadow-preferring and generalist species, we used OMM-OFM and WMM-WFM treatments. Indeed, a meadow-soil-preferring species will be more abundant in OMM or OMF blocks, 
while a forest-soil-preferring species will be more abundant in OFF or OFM blocks. When the type of soil had no significant effect on the abundance of a species, the species was considered as soilgeneralist. Otherwise, the parameters estimated from the GLM model indicated the soil preference of the species: (i) meadow-soil preferential species (MS), (ii) forest-soil preferential species (FS) and (iii) soil generalist species (SG).

\subsection{Relationship between land-use preference, soil preference and dispersal ability}

The relationship between the land-use preference and the dispersal ability of species was tested by a Fisher's exact test based on two-way contingency tables with classes of land-use preference (forest-specialist or meadow-specialist species depending on the land-use where dispersal was examined, forest- or meadow-preferring and generalist species) and classes of dispersal ability (species colonizing defaunated blocks within a week, within a month, within six months or more than six months) as entries. The relationships between soil preference and land-use preference or dispersal ability were tested in the same way with all land-use preferences and all dispersal abilities for soil preference modalities, except for the species for which there were not enough specimens to run the model (NR, Table 1). Finally, the relationship between dispersal abilities in two land-uses (forest and meadow) was also tested by the Fisher's exact test not taking into account species absent from the land-uses tested (modality M0 in the meadow and F0 in the forest).

\section{Results}

In the 120 soil blocks a total of 80,119 springtails were identified to species; 57 species were found in this study but only 49 species in untreated and untransferred blocks (WMM and WFF) for which dispersal ability and land-use preference were established (Table 1, Figure 2). 
222

Species could be classified according to their dispersal ability (Table 1). We found 18 species which dispersed within a week (nine in the forest, four in the meadow and five in both land-uses), one which dispersed after a week and within a month (in the forest), five which dispersed after a month and within six months (two in the forest and three in the meadow) and seven which did not disperse after six months (five in the forest and two in the meadow). However, as estimated from the colonization of defaunated blocks, dispersal abilities varied with the land-use (Table 1) and forest-preferring and meadow-preferring species could have different abilities to disperse depending on land-use (Table 2).

Species could be classified in decreasing affinity to the meadow and increasing affinity to the forest, using respective Indval values (Fig. 2). Only three species did not exhibit any preference for one habitat: Mesaphorura macrochaeta (Mes_mac), Lepidocyrtus lignorum (Lep_lig) and Lepidocyrtus lanuginosus (Lep_lan). A total of 19 species were forest-specialists, ten were meadowspecialists, nine were meadow-preferring and eight were forest-preferring species (Table 1).

Species could be classified according to their soil type preferences (Table 1). Five species were forest-soil-preferring, twenty were meadow-soil-preferring species and fifteen had no preference (i.e. soil generalists). For nine species, the total abundance of each species was too low to allow us running the analysis to determine their soil preference (i.e. NR modality in Table 1).

Our classes of land-use preference were validated: there is a significant interaction between sampling land-uses and land-use preference classes when taking into account the abundance of species or their presence/absence in WFF and WMM soil blocks (GLM, ANOVA test $\mathrm{p}<0.01$ ). A similar validation was achieved on classes of dispersal ability: there is a significant interaction between time of sampling and classes of dispersal ability when taking into account the presence/absence of species 
in OFF and OMM blocks (GLM, ANOVA test $\mathrm{p}<0.01$ ). Soil preference classes were directly validated by the GLM procedure that was used to build these classes.

There was a significant relationship between land-use preference and dispersal ability of species in the meadow (Table 3, Fig. 3a, Fisher's exact test, $\mathrm{p}<0.05$ ) but not in the forest (Table 3, Figure $3 b$, Fisher's exact test, $p>0.05$ ): the meadow soil was colonized more rapidly by meadow species than by forest species. Among forest species (forest-specialist and forest-preferring species), $4.1 \%$ (two species among a total of 49) colonized the blocks within a week in the meadow and 26.5\% (13 species among 49) in the forest (Table 2), while among meadow species (meadow-specialist and meadow-preferring species) $22.4 \%$ (11 species among 49) did so in the meadow and $10.2 \%$ (five species among 49) in the forest. However, $47 \%$ forest-specialist and 50\% forest-preferring species dispersed within a week in the forest while only $25 \%$ forest-preferring species did it in the meadow and $40 \%$ meadow-specialist and $77 \%$ meadow-preferring species dispersed within a week in the meadow while only $22 \%$ meadow-preferring species did it in the forest (Table 2). This confirmed that recolonization was more rapid in the meadow than in the forest.

There was no significant relationship between land-use preference and soil preference of species (Figure 3c, Fisher's exact test, $\mathrm{p}>0.05$ ): when transferred into the other land-use, forest as well as meadow species preferred the meadow soil. Only four among the 21 forest-specialist and forest-preferring species that could be tested showed a preference for the forest soil, while nine preferred the meadow soil and eight were indifferent (Table 1). Among the 16 meadow-specialist and meadow-preferring species that could be tested, ten showed a preference for the meadow soil, only one preferred the forest soil and five were indifferent. There was no significant relationship between soil preference and dispersal ability of species in the meadow and in the forest (Table 3, Figs. 3d, 3e, Fisher's exact test, $p>0.05$ ) and there was no significant relationship between the dispersal abilities of species in the meadow and in the forest (Table 3, Fig. 3f, Fisher's exact test, $\mathrm{p}>0.05$ ). 


\section{Discussion and conclusion}

274

By transferring soil blocks with and without their fauna between a forest and a meadow, we showed that habitat preference and dispersal ability of springtail species could be estimated, and that soil preference could be distinguished from land-use preference. We found 19 forest-specialist, eight forest-preferring, ten meadow-specialist, nine meadow-preferring and three generalist species. Concerning soil preference, we found five forest-soil-preferring, 20 meadow-soil-preferring and 15 soil-generalist species (nine were not categorized as they were too scarce). Within a week 17 species recolonized soil blocks in the meadow and 18 did it in the forest, while ten did not recolonize the blocks after six months in the meadow and 13 did not it in the forest. Land-use preference, soil preference and dispersal ability were largely independent from each other.

\subsection{Dispersal ability}

Given that they live in a dense and movement-impeding environment, litter- and soil-dwelling springtail species could be suspected at first sight to have low dispersal abilities (Rantalainen et al., 2008). However, our results showed that $37 \%$ of the species colonized $15 \mathrm{~cm}$ wide soil blocks in less than a week. Ponge et al. (2006) estimated the dispersal ability of 88 springtail species of the Morvan Natural Regional Park using several anatomical features: species with long legs and antennae, a functional jumping apparatus (furcula) and complete eye spots (eight ommatidies) were considered as able to disperse rapidly by their own means (Hopkin, 1997). Our results invalidate the overall principle of these predictions as there was no link between anatomical features and dispersal ability classes for half of the species (Table 1). For example, species such as Mesaphorura macrochaeta, Xenylla grisea and Friesea truncata, which have short legs and do not possess any functional jumping 
apparatus and thus were classified as slow-dispersal species by Ponge et al. (2006), were observed to colonize defaunated blocks within a week. Vannier (1975) studied the colonisation rate of springtails in soil columns of varying particle size distribution. Rapid colonization (less than a week) was mostly observed for species with long legs and antennae, developed furcula and complete visual apparatus. However, Neelidae (most probably Megalothorax minimus) were also shown to colonize rapidly soil columns. Megalothorax minimus was classified by Ponge et al. (2006) as a poorly dispersing species on the base of its anatomical features. In our experiment it was also shown to colonize the meadow soil (which it preferred) within a week (Table 1). Ojala and Huhta (2001) performed a microcosm experiment in which dispersal rates of springtail species could be measured at several distances of a colonisation source. They found that springtail species with high dispersal rates belonged to very different taxonomic groups: both Tullbergiinae (short legs and antennae, no furcula, no eyes) and Sminthuridae (opposite features) were active migrants. Dunger et al. (2002) followed experimentally over a year the colonisation of opencast mine dumps by Collembola. The first immigrant was a species with long legs, antenna and furcula and complete visual apparatus, Bourletiella pistillum, but the second immigrant was Mesaphorura florae a Tullbergiinae. In our study Mesaphorura macrochaeta (Tullbergiinae) exhibited high dispersal ability (colonization in less than a week) in the forest habitat. Discrepancies between aptitude for jump and walk and observed dispersal ability could be partially explained by passive dispersal which, however, has never been measured directly but was inferred from genetic exchange between distant populations of the epigeic springtail Orchesella cincta (Van der Wurff et al., 2003). Rightly, Dunger et al. (2002) did not attribute to passive dispersal by wind a prominent influence, except for the first immigrant, B. pistillum. We cannot rule out that other mechanisms of passive dispersal such as phoresy or egg transport could help some poorly mobile species to reach remote places, as this has been shown in aquatic invertebrates (Frisch et al., 2007), which might explain discrepancies between predicted (on the base of anatomy) and observed colonisation rates by springtail species.

\subsection{Land-use preference}


For $85 \%$ of the species we sampled there was a fairly good correspondence between land-use

326

327 preferences estimated in our experiment and already published results (Table 1). However, some species (Arrhopalites principalis, Dicyrtomina minuta, Entomobrya multifasciata, Folsomia manolachei, Friesea truncata, Isotomiella minor, Neanura muscorum, Orchesella cincta, Paratullbergia callipygos, Pogonognathellus flavescens, Pseudachorutes parvulus, Sphaeridia pumilis, Subisotoma pusilla) were classified in our study as forest- or meadow- specialists while, according to literature, they can be found in both habitats (Ponge, 1980; Rusek, 1989; Ponge, 1993; Dombos, 2001; Ponge et al., 2003; Petersen et al., 2004; Kuznetsova, 2006; Ponge et al., 2006; Chauvat et al., 2007) and should be classified as preferring or generalist but not specialist species. This could be due to local environmental peculiarities that did not allow these species to live in both habitats, such as differences in soil condition (humus form). It should also be noted that in the present study land-use preferences were estimated from a limited set of IndVal values and thus cannot be extrapolated to a variety of environments, contrary to studies cited above.

\subsection{Soil preference}

Species known for their strong affinity to acid soils, such as Lipothrix lubbocki and Willemia anophthalma (Ponge, 1980; Hågvar and Abrahamsen, 1984; Ponge, 1993) exhibited a preference for the forest soil, in accordance with its Dysmoder humus form. Conversely, species which are repelled by soil acidity, such as Sminthurinus aureus and Heteromurus nitidus (Ponge, 1980, 1993; Salmon and Ponge, 1999) preferred the meadow soil, in accordance with its Eumull humus form. However, the preference for the forest soil exhibited by Sphaeridia pumilis, a species which we classified as meadow-specialist according to its distribution in our sites (the present study), seems to be contradictory. However, as this species, according to its distribution observed by Ponge et al. (2003) in the same regional context, should be meadow-preferring rather than meadow-specialist, the result 
obtained here is probably due to a stochastic effect of its lower abundance in the forest. Together with our results on land-use preference (see above), this study points to other, still imperfectly explored, environmental features that could be meaningful for Collembola. Microclimate, which differs to a great extent between forest and meadow (Morecroft et al., 1998), has a decisive influence on the survival of these moisture-sensitive tiny arthropods (Betsch and Vannier, 1977; Tsiafouli et al., 2005). Biotic interactions such as competition are also thought to influence species distribution (Hågvar, 1990; Christiansen et al., 1992; Theenhaus et al., 1999; Salmon and Ponge, 2001; Krivtsov et al., 2003; Salmon et al., 2005). Hågvar (1990) suggested that oribatid species living commonly in Dysmoder (acid-tolerant species) dominate in forest soils, not because they are attracted to acidity, but rather because they compete better with acid-intolerant species. Indeed, competition with resident species can impede a local patch to be colonized by dispersing individuals of other species: competition can thus decrease the realized niche of species (Shigesada and Kawasaki, 1997). Hints on the effect of inter-specific competition could be given in the future by the comparison of our defaunated and untreated blocks.

To the present state of our knowledge it is not be possible to establish a link between habitat preference (including soil preference) and morphological traits of Collembola, although Ponge (2000) noted that extant springtail species or species groups with ancestral anatomical characters exhibited a higher tolerance to soil acidity, as ascertained by their present-day distribution.

\subsection{Interactions between dispersal ability, land-use preference and soil preference}

The attractiveness of the meadow soil (Fig. 3c) for a majority of forest as well as meadow specialist and preferring species needs to be interpreted. The meadow humus form was a Eumull, which contrasts with the Dysmoder into which it was transferred in our experiment. It has been 
demonstrated that soils with high earthworm activity, such as our meadow soil, are attractive for many arthropod species and particularly for Collembolan species (Hamilton and Sillman, 1989; Loranger et al., 1998; Salmon and Ponge, 1999; Maraun et al., 1999). Earthworm activity, which is usually high in Eumull (Brêthes et al., 1995), provides food and habitat for many subterranean organisms, mainly through bioturbation and redistribution of organic matter in the topsoil (Scheu, 1987), and protection against predation offered by earthworm burrows (Salmon et al., 2005). That forest species could be attracted to Eumull (with prominent earthworm activity) while they are commonly living in Dysmoder with poor earthworm activity (Brêthes et al., 1995), and are absent from the nearby meadow, might indicate that their achieved distribution is due to a trade-off between (i) their preference for soils with more favourable biotic interactions (food included) and (ii) their eco-physiological constraints (sensitivity to desiccation, waterlogging, frost) which can be easier fulfilled in sheltered woodland microclimate conditions.

Although we did not detect any link between dispersal ability in the forest and the type of land-use preference (Fig. 3b), there was a significant correlation between dispersal ability in the meadow and the type of land-use preference (Fig. 3a): in the meadow, meadow-specialist and meadow-preferring species disperse more quickly than forest-preferring species. This suggests that dispersal in the meadow was easier than in the forest. An explanation could be that the meadow represents a disturbed habitat for Collembola, so that meadow species need to be more mobile to persist in this land-use. Indeed, forests are more stable habitats as the establishment of a mature forest takes several decades (Ponge et al., 1998) whereas a meadow is usually ploughed and replanted each ten years. Temperature range and soil compression due to cattle trampling are higher in meadow than in forest (Friberg et al., 2008). Thus forest Collembolan species would not have evolved towards high dispersal abilities because their environment was stable, thereby confirming previous results obtained by Ponge et al. (2008). The absence of correlation between dispersal ability in the forest and land use preference would be explained by the lack of attractiveness of the forest soil for most species (see above). In the light of our results and according to Mysrerud and Ims (1998), it can be suggested that 
402 (1) Collembolan species can be attracted to another soil than that of their current habitat, (2) this does not impede them to persist in this habitat if food is abundant enough. In the example of Vertagopus arboreus, tree trunks are known to be favoured temporary habitats, in both disturbed and undisturbed environments (Ponge, 1993; Prinzing, 2001).

We did not detect any link between dispersal ability, either in the meadow or in the forest, and soil preference. However, as noticed above, we found a link between land-use preference and dispersal ability in the meadow. If we combine these results with the abovementioned attractiveness of the meadow soil, and the fact that we did not detect any significant relationship between meadow- and forest-dispersal abilities, this points to species-specific barriers to colonization, which do not necessarily match soil preferences. The freezing procedure which was used to deprive the blocks from their original fauna could make the forest soil somewhat distasteful for some species: it has been shown that freezing, by splitting macromolecular assemblages, may increase the toxicity of carbonrich sediments (Geffard et al., 2004).

\subsection{Working hypotheses and perspectives}

Our results do not support the hypothesis that land-use-specialist species are also soilspecialists of the corresponding soil. However the meadow soil was more attractive whatever the landuse preference of the species, suggesting that food resources must be an important dispersal-triggering stimulus. This is supported by Bengtsson et al. (1994) who experimentally showed that the dispersal rate decreased as food resources increased in Collembolan populations. Our results do not fully support our second hypothesis that land use generalists have higher dispersal ability than specialists. This hypothesis was supported for dispersal in the meadow but the idea that dispersal is not counterselected for habitat specialists (and vice versa) is not supported. However, the selection of more 
mobile species in the more disturbed land-use (the meadow) supports the hypothesis that dispersal and habitat-preference strategies of species have been selected to allow them to recolonize quickly soil patches after a disturbance. It would also be interesting to further investigate whether disturbed habitats have led to the selection of species that can survive disturbances. Indeed, temperature variability is stronger in meadows than in forests (Friberg et al., 2008) and Collembola are known to be sensitive to temperature (Betsch and Vannier, 1977). Moreover, springtails have already been shown to have evolved different eco-physiological strategies to resist disturbance by selecting speciesspecific traits such as, among others, diapausing eggs (Leinaas and Bleken, 1983) and light avoidance (Salmon and Ponge, 1998). More generally, the absence of relationship between species traits (i.e. dispersal ability, land-use preference and soil preference), except in the case of land-use preference and dispersal in the meadow, suggests that these species characteristics were selected mostly independently. Because Collembolan life-history is probably constrained by many trade-offs (Tully et al., 2006), this might also mean that more traits have to be documented to find a general pattern. dispersal for springtails. Indeed, there are still very few studies on dispersal in Collembola but existing ones suggest that Collembolan movements influence their population dynamics (Bengtsson et al., 1994, 2002). For example, dispersal can be a way to avoid intra-specific competition. Moreover, if the role of facilitation or competitive exclusion is established as a mechanism structuring local species assemblages (Connell \& Slatyer, 1977), the role of inter-specific competition was never tested for springtails. The design of our experimental protocol will allow us to investigate further these issues.

\section{Acknowledgements}


(IFB, awarded by FD). The junior author (AA) performed her MSc thesis with this experimental

material. The authors are also indebted to the Morvan Natural Regional Park and to a private owner for free access to study sites, and to P. Lavelle for encouraging our ideas in his research staff.

\section{References}

Adolphe, J.P., Desmanèges-Lorenz, J., 1977. Géologie buissonnière en Morvan, $2^{\text {nd }}$ ed. Bureau de Recherches Géologiques et Minières, Orléans.

Andrén, H., Delin A., Seiler, A., 1997. Population response to landscape changes depends on specialization to different landscape elements. Oikos 80, 193-196.

Bengtsson, G., Hedlund, K., Rundgren, S., 1994. Food- and density-dependent dispersal: evidence from a soil Collembolan. Journal of Animal Ecology 63, 513-520.

Bengtsson, G., Rydén, T., Sjögren Öhrn, M., Wiktorsson, M., 2002. Statistical analysis of the influence of conspecifics on the dispersal of soil Collembola. Theoretical Population Biology $61,97-113$.

Betsch, J.M., Vannier, G., 1977. Caractérisation des deux phases juvéniles d'Allacma fusca (Collembola, Symphypleona) par leur morphologie et leur écophysiologie. Zeitschrift für Zoologische Systematik und Evolutionsforschung 15, 124-141. 
475 Brêthes, A., Brun, J.J., Jabiol, B., Ponge, J.F., Toutain, F., 1995. Classification of French humus forms: a French proposal. Annales des Sciences Forestières 52, 535-546.

Chauvat, M., Wolters, V., Dauber, J., 2007. Response of collembolan communities to land-use change and grassland succession. Ecography 30, 183-192.

480

481

Christiansen, K., Doyle, M., Kahlert, M., Gobaleza, D., 1992. Interspecific interactions between collembolan populations in culture. Pedobiologia 36, 274-286.

483

Clobert, J., Danchin, E., Dhondt, A.A., Nichols, J.D. 2001. Dispersal. Oxford University Press, 485 Oxford.

Connell, J.H., Slatyer, R.O. 1977. Mechanisms of succession in natural communities and their role in community stability and organization. The American Naturalist 111, 1119-1144.

489

Crawley, M.J., 2007. The R Book. Wiley, New York. composition. Soil Biology and Biochemistry 33, 2037-2045. 
Drake, J.A., 1990. Communities as assembled structures: do rules govern pattern? Trends in Ecology and Evolution 5, 159-164.

Dufrêne, M., Legendre, P., 1997. Species assemblages and indicator species: the need for a flexible asymmetrical approach. Ecological Monographs 67, 345-366.

Dunger, W., Schulz, H.J., Zimdars, B., 2002. Colonization behaviour of Collembola under different conditions of dispersal. Pedobiologia 46, 316-327.

Dunning, J.B., Danielson B.J., Pulliam, H.R., 1992. Ecological processes that affect populations in complex landscapes. Oikos 65, 169-175.

Fédoroff, N., Aurousseau, P., 1981. Micromorphologie des sols bruns acides sur matériau granitique. Canadian Journal of Soil Science 61, 483-496.

Friberg, M., Olofsson, M., Berger, D., Karlsson, B., Wiklund, C., 2008. Habitat choice precedes host plant choice: niche separation in a species pair of a generalist and a specialist butterfly. Oikos $117,1337-1344$.

Frisch, D., Green, A.J., Figuerola, J., 2007. High dispersal capacity of a broad spectrum of aquatic invertebrates via waterbirds. Aquatic Sciences 69, 568-574. 
517 Geffard, O., His, E., Budzinski, H., Chiffoleau, J.F., Coynel, A., Etcheber, H., 2004. Effects of storage method and duration on the toxicity of marine sediments to embryos of Crassostrea gigas oysters. Environmental Pollution 129, 457-465.

520

Gisin, H., 1960. Collembolenfauna Europas. Muséum d'Histoire Naturelle, Geneva.

Hågvar, S., 1990. Reactions to soil acidification in microarthropods: is competition a key factor? Biology and Fertility of Soils 9, 178-181.

Hågvar, S., Abrahamsen, G., 1984. Collembola in Norwegian coniferous forest soils. III. Relations to soil chemistry. Pedobiologia 27, 331-339.

Hamilton, W.E., Sillman, D.Y., 1989. Influence of earthworm middens on the distribution of soil microarthropods. Biology and Fertility of Soils 8, 279-284.

Hättenschwiler, S., Tiunov, A.V., Scheu, S., 2005. Biodiversity and litter decomposition in terrestrial ecosystems. Annual Review of Ecology, Evolution and Systematics 36, 191-218.

Hopkin, S.P., 1997. Biology of the Springtails. Oxford University Press, Oxford.

Hopkin, S.P., 2007. A Key to the Collembola (Springtails) of Britain and Ireland. Field Studies Council, Shrewsbury. 
540 Hunter, M.D., Price, P.W., 1992. Playing chutes and ladders: heterogeneity and the relative forces of bottom-up and top-down forces in natural communities. Ecology 73, 724-732.

Ihaka, R., Gentleman, R., 1996. R: a language for data analysis and graphics. Journal of Computational and Graphical Statistics 5, 299-314.

Keddy, P.A., 1992. Assembly and response rules: two goals for predictive community ecology. Journal of Vegetation Science 3, 157-164.

Krivtsov, V., Illian, J.B., Liddell, K., Garside, A., Bezginova, T., Salmond, R., Thompson, J., complex interactions involving soil mesofauna: analysis of the results from a Scottish woodland. Ecological Modelling 170, 441-452.

Kuznetsova, N.A., 2006. Long-term dynamics of Collembola in two contrasting ecosystems. Pedobiologia 50, 157-164.

Lavelle, P., Spain, A.V., 2005. Soil Ecology. Springer, Berlin. Fabricius (Collembola; Entomobryidae). Oecologia 58, 194-199. 
Loranger, G., Ponge, J.F., Blanchart, E., Lavelle, P., 1998. Impact of earthworms on the distribution of microarthropods in a vertisol (Martinique). Biology and Fertility of Soils 27, 21-26.

Maraun, M., Alphei, J., Bonkowski, M., Buryn, R., Migge, S., Peter, M., Schaefer, M., Scheu, S., 1999. Middens of the earthworm Lumbricus terrestris (Lumbricidae) microhabitats for microand mesofauna in forest soil. Pedobiologia 43, 276-287.

Morecroft, M.D., Taylor, M.E., Oliver, H.R., 1998. Air and soil microclimates of deciduous woodland compared to an open site. Agricultural and Forest Meteorology 90, 141-156.

Mysrerud, A., Ims, R.A., 1998. Functional responses in habitat use: availability influences relative use in trade-off situations. Ecology 79, 1435-1441.

Ojala, R., Huhta, V., 2001. Dispersal of microarthropods in forest soil. Pedobiologia 45, 443-450.

Petersen, H., Jucevica, E., Gjelstrup, P., 2004. Long-term changes in collembolan communities in grazed and non-grazed abandoned arable fields in Denmark. Pedobiologia 48, 559-573. 
582

Ponge, J.F., 1980. Les biocénoses des Collemboles de la forêt de Sénart. In: Pesson, P. (Ed.), Actualités d'Écologie Forestière. Gauthier-Villars, Paris, pp. 151-176.

Ponge, J.F., 1993. Biocenoses of Collembola in atlantic temperate grass-woodland ecosystems. Pedobiologia 37, 223-244.

Ponge, J.F., 2000. Acidophilic Collembola: living fossils? Contributions from the Biological Laboratories, Kyoto University 29, 65-74.

Ponge, J.F., André, J., Zackrizzon, O., Bernier, N., Nilsson, M.C., Gallet, C., 1998. The forest regeneration puzzle: biological mechanisms in humus layer and forest vegetation dynamics. BioScience 48, 523-530.

Ponge, J.F., Dubs, F., Gillet, S., Sousa, J.P., Lavelle, P., 2006. Decreased biodiversity in soil sprungtail communities: the importance of dispersal and landuse history in heterogeneous landscapes. Soil Biology and Biochemistry 38, 1158-1161.

Ponge, J.F., Gillet, S., Dubs, F., Fédoroff, E., Haese, L., Sousa, J.P., Lavelle, P., 2003. Collembolan communities as bioindicators of land use intensification. Soil Biology and Biochemistry 35, 813-826.

Ponge, J.F., Tully, T., Gins, A., 2008. Short-term responses of two collembolan communities after abrupt environmental perturbation: a field experimental approach. Pedobiologia 52, 19-28. 
606

607

608

609

610

611

612

613

614

615

616

617

618

619

620

621

622

623

624

625

626

Potapow, M., 2001. Synopses of Palaearctic Colembola. III. Isotomidae. Abhandlungen und Berichte des Naturkundemuseums Görlitz 73, 1-603.

Prinzing, A.J., 2001. Use of shifting microclimatic mosaics by arthropods on exposed tree trunks. Annals of the Entomological Society of America 94, 210-218.

Rajaniemi, T.K., Goldberg, D.E., Turkington, R., Dyer, A.R., 2006. Quantitative partitioning of regional and local processes shaping regional diversity patterns. Ecology Letters 9, 121-128.

Rantalainen, M.L., Haimi, J., Fritze, H., Pennanen, T., Setälä, H., 2008. Soil decomposer community as a model system in studying the effects of habitat fragmentation and habitat corridors. Soil Biology and Biochemistry 40, 861-871.

Ribera I., Dolédec S., Downie I., S. \& Foster G., N. 2001. Effect of land disturbance and stress on species traits of ground beetle assemblages. Ecology, 82, 1112-1129.

Rusek, J., 1989. Ecology of Collembola. In: Dallai, R. (Ed.), Third International Seminar on Apterygota, Siena, Italy, August 1989. University of Siena, Siena, pp. 271-281.

Rusek, F., 1998. Biodiversity of Collembola and their functional role in the ecosystem. Biodiversity and Conservation 7, 1207-1219. 
628

630

631

632

633

634

635

636

637

638

639

640

641

642

643

644

645

646

647

648

Salmon, S., Geoffroy, J.J., Ponge, J.F., 2005. Earthworms and Collembola relationships: effects of predatory centipedes and humus forms. Soil Biology and Biochemistry 37, 487-495.

Salmon, S., Ponge, J.F., 1999. Distribution of Heteromurus nitidus (Hexapoda, Collembola) according to soil acidity: interactions with earthworms and predator pressure. Soil Biology and Biochemistry 31, 1161-1170.

Salmon, S., Ponge, J.F., 2001. Earthworm excreta attract soil springtails: laboratory experiments on Heteromurus nitidus (Collembola: Entomobryidae). Soil Biology and Biochemistry 33, 19591969.

Scheu, S., 1987. The role of substrate feeding earthworms (Lumbricidae) for bioturbation in a beechwood soil. Oecologia 72, 192-196.

Shigesada, N., Kawasaki, K., 1997. Biological Invasions: Theory and Practice. Oxford University Press, Oxford.

Sousa, J.P., Bolger, T., da Gama, M.M., Lukkari, T., Ponge, J.F., Simón, C., Traser, G., Vanbergen, A.J., Brennan, A., Dubs, F., Ivits, E., Keating, A., Stofer, S., Watt, A.D., 2006. Changes in Collembola richness and diversity along a gradient of land-use intensity: a pan European study. Pedobiologia 50, 147-156. 
650 Tews, J., Brose, U., Grimm, V., Tielbörger, K., Wichmann, M.C., Schwager, M., Jeltsch, F., 2004.

651

652

653

654

655

656

657

658

659

660

661

662

663

664

665

666

667

668

669

670

671 Animal species diversity driven by habitat heterogeneity/diversity: the importance of keystone structures. Journal of Biogeography 31, 79-92.

Theenhaus, A., Scheu, S., Schaefer, M., 1999. Contramensal interactions between two collembolan species: effects on population development and on soil processes. Functional Ecology 13, 238246.

Thibaud, J.M., Schulz, H.J., da Gama Assalino, M.M., 2004. Synopses on Palaearctic Collembola. IV. Hypogastruridae. Abhandlungen und Berichte des Naturkundemuseums Görlitz 75, 1-287.

Tsiafouli, M.A., Kallimanis, A.S., Katana, E., Stamou, G.P., Sgardelis, S.P., 2005. Responses of soil microarthropods to experimental short-term manipulations of soil moisture. Applied Soil Ecology 29, 17-26.

Tully, T., d'Haese, C., Richard, M., Ferrière, R., 2006. Two major evolutionary lineages revealed by molecular phylogeny in the parthenogenetic collembola species Folsomia candida. Pedobiologia 50, 95-104.

Van der Wurff, A.W.G., Isaaks, J.A., Ernsting, G., Van Straalen, N.M., 2003. Population substructures in the soil invertebrate Orchesella cincta, as revealed by microsatellite and TE-AFLP markers. Molecular Ecology 12, 1349-1359. 
673 Vannier, G., 1975. Étude in situ du retour des microarthropodes sur des fractions de sol de 674 granulométrie différente. Bulletin d'Écologie 6, 87-98.

675

676 Weiher, E., Keddy, P., 2001. Ecological Assembly Rules: Perspectives, Advances, Retreats. 677 Cambridge University Press, Cambridge.

678

679 Zimdars, B., Dunger, W., 1994. Synopses on Palaearctic Collembola. I. Tullbergiinae. Abhandlungen 680 und Berichte des Naturkundemuseums Görlitz 68, 1-71.

681

682 Zobel, M., 1997. The relative role of species pools in determining plant species richness: an alternative 683 explanation of species coexistence? Trends in Ecology and Evolution 12, 266-269.

684 
685

686

687

688

689

690

691

692

693

694

695

696

697

698

699

700

701

702

\section{Figure captions}

Figure 1. Experimental design of soil block transfer between a forest and a nearby meadow. Gray arrows represent soil blocks transferred in the other land-use. Upper case letters indicate treatment codes (refer to text in Section 2.2 for symbols)

Figure 2. Graphical representation of the distribution of Collembolan species between the forest and the meadow according to IndVal values for meadow (light grey) and forest (black). Full light grey lines indicate species specialist of the meadow and full black lines indicate species specialist of the forest. Dotted and dashed light grey lines indicate species preferential of the meadow and black ones the same for the forest. Full dark grey lines indicate generalist species, i.e. species did not displaying any preference for one or the other land-use

Figure 3. Distribution of species according to different response traits. Trait classes in abscissa, number of species in ordinate (refer to text or to Table 1 for symbols). (a) Land-use preference. (b) Dispersal ability in the meadow. (c) Dispersal ability in the forest. (d) Soil preference 
Table 1. Land-use preference, dispersal ability and nature of soil preference for springtail species used in the soil transfer experiment. Land use preference: $\mathrm{F}$ = forest-specialist or strict forest species, $\mathrm{FP}=$ forest-preferring species, $\mathrm{M}=$ meadow-specialist or strict meadow species, $\mathrm{MP}=$ meadow-preferring species, $\mathrm{G}$ = land-use generalist species. Dispersal ability in meadow: $M 0=$ species absent in the meadow, $M 1=$ species which colonized meadow frozen blocks within a week, $\mathrm{M} 2=$ species which colonized meadow frozen blocks after a week and within a month, $\mathrm{M} 3=$ species which colonized meadow frozen blocks after a month and within six months, M4 = species which did not colonize meadow frozen blocks within six months. Dispersal ability in forest: F0 = species absent in the forest, F1 = species which colonized forest frozen blocks within a week, F2 = species which colonized forest frozen blocks after a week and within a month, F3 = species which colonized forest frozen blocks after a month and within six months, F4 = species which did not colonize forest frozen blocks within six months. Soil preference: FS = forest-soil-preferring species, MS = meadow-soil-preferring species, $S G$ = soil-generalist species. NR: not enough specimens to run the model

\begin{tabular}{|c|c|c|c|c|c|c|c|}
\hline \multirow{2}{*}{ Species name } & \multirow{2}{*}{ Species code } & \multirow{2}{*}{$\begin{array}{l}\text { Land use } \\
\text { preference }\end{array}$} & \multicolumn{2}{|c|}{ Dispersal ability } & \multirow{2}{*}{$\begin{array}{c}\text { Soil } \\
\text { preference }\end{array}$} & \multirow{2}{*}{$\begin{array}{c}\text { Dispersal type } \\
\text { (from Ponge et al., } \\
\text { 2006) }\end{array}$} & \multirow{2}{*}{$\begin{array}{l}\text { Habitat preference } \\
\text { (from Ponge et al., } \\
\text { 2006) }\end{array}$} \\
\hline & & & in the meadow & in the forest & & & \\
\hline Allacma fusca & All_fus & $\mathrm{F}$ & M0 & F4 & NR & Fast & Woodland \\
\hline Arrhopalites principalis & Arr_pri & $\mathrm{F}$ & M0 & F4 & MS & & \\
\hline Arrhopalites sericus & Arr_ser & $\mathrm{FP}$ & M4 & $\mathrm{F} 1$ & MS & & \\
\hline Ceratophysella denticulata & Cer_den & MP & M1 & F4 & MS & & \\
\hline Ceratophysella recta & Cer_rec & $\mathrm{FP}$ & M4 & F3 & MS & & \\
\hline Deuteraphorura inermis & Deu_ine & FP & M4 & $\mathrm{F} 1$ & MS & & \\
\hline Deuterosminthurus sulphureus & Deu_sul & M & M3 & Fo & MS & Fast & Agricultural land \\
\hline Dicyrtomina minuta & Dic_min & $\mathrm{F}$ & Mo & $\mathrm{F} 1$ & FS & Fast & Agricultural land \\
\hline Entomobrya multifasciata & Ent_mul & $\mathrm{F}$ & M3 & F4 & NR & Fast & Agricultural land \\
\hline Folsomia listeri & Fol_lis & M & M4 & Fo & NR & & \\
\hline Folsomia manolachei & Fol_man & M & M1 & Fo & MS & & \\
\hline Folsomia quadrioculata & Fol_qua & FP & M1 & $\mathrm{F} 1$ & MS & Slow & Woodland \\
\hline Friesea truncata & Fri_tru & $\mathrm{F}$ & Mo & $\mathrm{F} 1$ & $S G$ & Slow & Woodland \\
\hline Gisinianus flammeolus & Gis_fla & $\mathrm{F}$ & Mo & F4 & NR & & \\
\hline Heteromurus nitidus & Het_nit & $M$ & M1 & Fo & MS & Slow & Agricultural land \\
\hline Isotoma anglicana & Iso_ang & MP & M1 & F4 & MS & & \\
\hline Isotomiella minor & Iso_min & $\mathrm{F}$ & Mo & $\mathrm{F} 1$ & MS & Slow & Woodland \\
\hline Lepidocyrtus cyaneus & Lep_cya & M & M1 & Fo & $S G$ & Fast & Agricultural land \\
\hline Lepidocyrtus lanuginosus & Lep_lan & $\mathrm{G}$ & M1 & $\mathrm{F} 1$ & SG & Fast & Woodland \\
\hline Lepidocyrtus lignorum & Lep_lig & $G$ & M1 & $\mathrm{F} 1$ & SG & Fast & Agricultural land \\
\hline Lipothrix lubbocki & Lip_lub & $\mathrm{F}$ & Mo & F2 & FS & Fast & Woodland \\
\hline Megalothorax minimus & Meg_min & MP & M1 & F3 & MS & Slow & Woodland \\
\hline Mesaphorura florae & Mes_flo & M & M3 & Fo & MS & & \\
\hline Mesaphorura macrochaeta & Mes_mac & $\mathrm{G}$ & M2 & $\mathrm{F} 1$ & MS & Slow & Woodland \\
\hline Micranurida pygmaea & Mic_pyg & MP & M4 & F3 & NR & Slow & Woodland \\
\hline Micraphorura absoloni & Mic_abs & $\mathrm{F}$ & Mo & F4 & NR & Slow & Woodland \\
\hline Neanura muscorum & Nea_mus & $\mathrm{F}$ & Mo & F3 & SG & Slow & Woodland \\
\hline Orchesella cincta & Orc_cin & $\mathrm{F}$ & Mo & F3 & MS & Fast & Woodland \\
\hline Paratullbergia callipygos & Par_cal & $\mathrm{F}$ & M0 & F4 & NR & Slow & Woodland \\
\hline Parisotoma notabilis & Par_not & MP & M1 & F1 & SG & Slow & Agricultural land \\
\hline Pogonognathellus flavescens & Pog_fla & $\mathrm{F}$ & Mo & $\mathrm{F} 1$ & SG & Fast & Woodland \\
\hline Protaphorura aurantiaca & Pro_aur & MP & M1 & F4 & $S G$ & & \\
\hline Pseudachorutes parvulus & Pse_par & $\mathrm{F}$ & Mo & $\mathrm{F} 1$ & SG & Slow & Woodland \\
\hline Pseudosinella alba & Pse_alb & MP & M1 & F4 & $S G$ & Slow & Agricultural land \\
\hline Pseudosinella terricola & Pse_ter & $\mathrm{F}$ & Mo & F1 & SG & & \\
\hline Sminthurides parvulus & Smi_par & $M$ & M3 & Fo & SG & Fast & Agricultural land \\
\hline Sminthurides schoetti & Smi_sch & MP & M2 & F4 & MS & Fast & Agricultural land \\
\hline Sminthurinus aureus & Smi_aur & MP & M1 & $\mathrm{F} 1$ & MS & Fast & Agricultural land \\
\hline Sminthurinus signatus & Smi_sig & $\mathrm{F}$ & Mo & $\mathrm{F} 1$ & SG & Fast & Woodland \\
\hline Sminthurus viridis & Smi_vir & M & M1 & Fo & MS & Fast & Agricultural land \\
\hline Sphaeridia pumilis & Sph_pum & M & M4 & F3 & FS & Fast & Agricultural land \\
\hline Stenaphorura denisi & Steph_de & $M$ & M4 & Fo & $N R$ & Slow & Agricultural land \\
\hline Stenognathellus denisi & Stegn_de & $\mathrm{F}$ & Mo & $\mathrm{F} 1$ & FS & & \\
\hline Subisotoma pusilla & Sub_pus & $\mathrm{F}$ & M3 & $\mathrm{F} 4$ & NR & & \\
\hline Vertagopus arboreus & Ver_arb & $\mathrm{FP}$ & M1 & F4 & MS & Fast & Woodland \\
\hline Willemia anophthalma & Wil_ano & $\mathrm{FP}$ & M4 & $\mathrm{F} 2$ & FS & Slow & Woodland \\
\hline Willemia denisi & Wil_den & $\mathrm{FP}$ & M4 & F3 & MS & Slow & Woodland \\
\hline Xenylla grisea & Xen_gri & $\mathrm{F}$ & Mo & $\mathrm{F} 1$ & $S G$ & Slow & Woodland \\
\hline Xenylla tullbergi & Xen_tul & FP & M4 & $\mathrm{F} 1$ & SG & Slow & Woodland \\
\hline
\end{tabular}


Table 2. Crossed relationships between categories of land-use preference and dispersal ability. Data are numbers of species belonging to each crossed category. Marginal totals are indicated in italic type. Same codes for categories as in Fig. 3

Dispersal ability in the forest (F0 to F4) and in the meadow (M0 to M4)

\begin{tabular}{lllllll}
\hline & M0 & M1 & M2 & M3 & M4 & \\
F0 & 0 & 4 & 0 & 3 & 2 & 9 \\
F1 & 9 & 5 & 1 & 0 & 3 & 18 \\
F2 & 1 & 0 & 0 & 0 & 1 & 2 \\
F3 & 2 & 1 & 0 & 0 & 4 & 7 \\
F4 & 5 & 5 & 1 & 2 & 0 & 13 \\
& 17 & 15 & 2 & 5 & 10 & 49 \\
\hline
\end{tabular}

Dispersal ability of land-use preference categories in the meadow

\begin{tabular}{lllllll}
\hline & M0 & M1 & M2 & M3 & M4 & \\
F & 17 & 0 & 0 & 2 & 0 & 19 \\
FP & 0 & 2 & 0 & 0 & 6 & 8 \\
M & 0 & 4 & 0 & 3 & 3 & 10 \\
MP & 0 & 7 & 1 & 0 & 1 & 9 \\
G & 0 & 2 & 1 & 0 & 0 & 3 \\
& 17 & 15 & 2 & 5 & 10 & 49 \\
\hline
\end{tabular}

Dispersal ability of land-use preference catagories in the forest

\begin{tabular}{lllllll}
\hline & F0 & F1 & F2 & F3 & F4 & \\
F & 0 & 9 & 1 & 2 & 7 & 19 \\
FP & 0 & 4 & 1 & 2 & 1 & 8 \\
M & 9 & 0 & 0 & 1 & 0 & 10 \\
MP & 0 & 2 & 0 & 2 & 5 & 9 \\
G & 0 & 3 & 0 & 0 & 0 & 3 \\
& 9 & 18 & 2 & 7 & 13 & 49 \\
\hline
\end{tabular}


Table 3. Links between land-use preference, dispersal ability and nature of soil-preference for springtail species tested by the Fisher's exact test.

LUP: Land-use preference. DAM: Dispersal ability in the meadow. DAF: Dispersal ability in the forest. SP: Soil preference. (1)

Modalities used: $M=$ meadow-specialist species, MP = meadow-preferring species, $G$ = land-use generalist species. (2) Modalities used: $F=$ forest-specialist species, $F P=$ forest-preferring species, $\mathrm{G}$ = habitat generalist species. (3) All modalities used except species for which there were not enough specimens to run the model. (4) All modalities used except $\mathrm{M0}=$ species absent in the meadow and $\mathrm{F} 0=$ species absent in the forest. ${ }^{*}=$ Significant at 0.05 level. NS = not significant

\begin{tabular}{llll}
\hline & LUP & DAM & DAF \\
\hline DAM & ${ }^{*}(1)$ & & \\
DAF & NS (2) & NS (4) & \\
SP & NS (3) & NS (3) & NS (3) \\
\hline
\end{tabular}


709

710

711

712

713

714

715

716

717

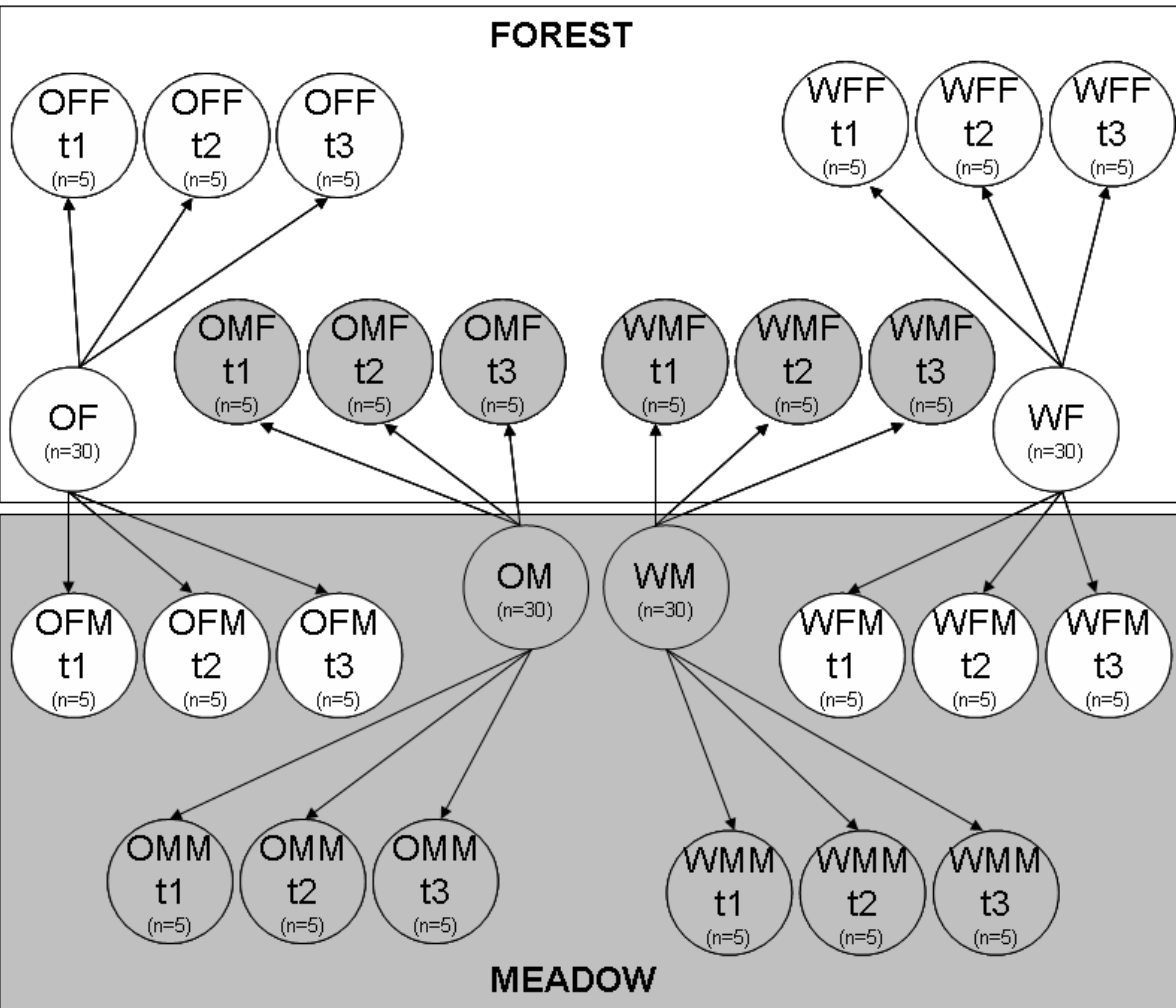

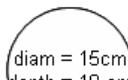

depth $=10 \mathrm{~cm}$

Transferred

block

718

719

Figure 1

720 
721

723

724

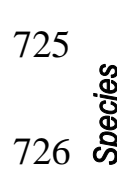

727

728

729

730

731

732

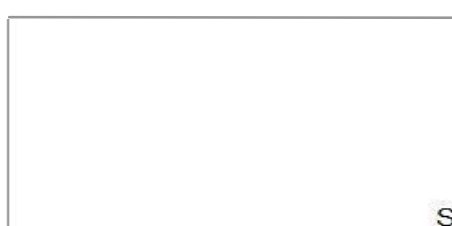

Pse_ter

Iso-min

Fol-qua

rol_qua

Xen_gri

Xegn de

Lip_lub

Nea_mus

Wil_ano

Smi_sig

Gis_fla

Ent_mul

Cer rec

Par cal

Arr_pri

Mes_mac

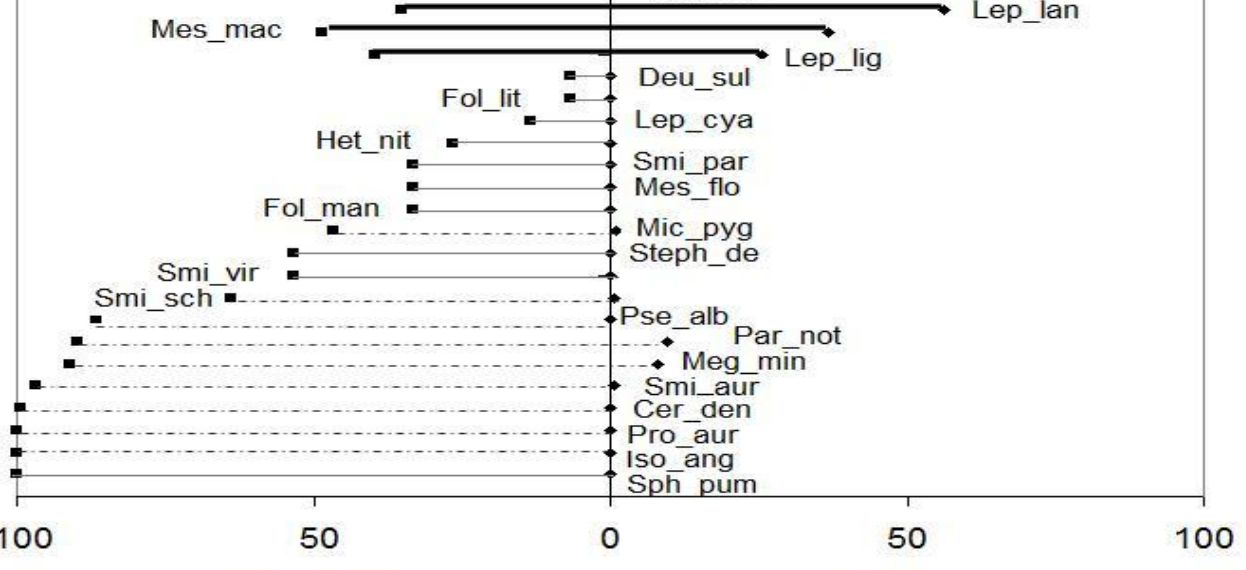

- All_fus

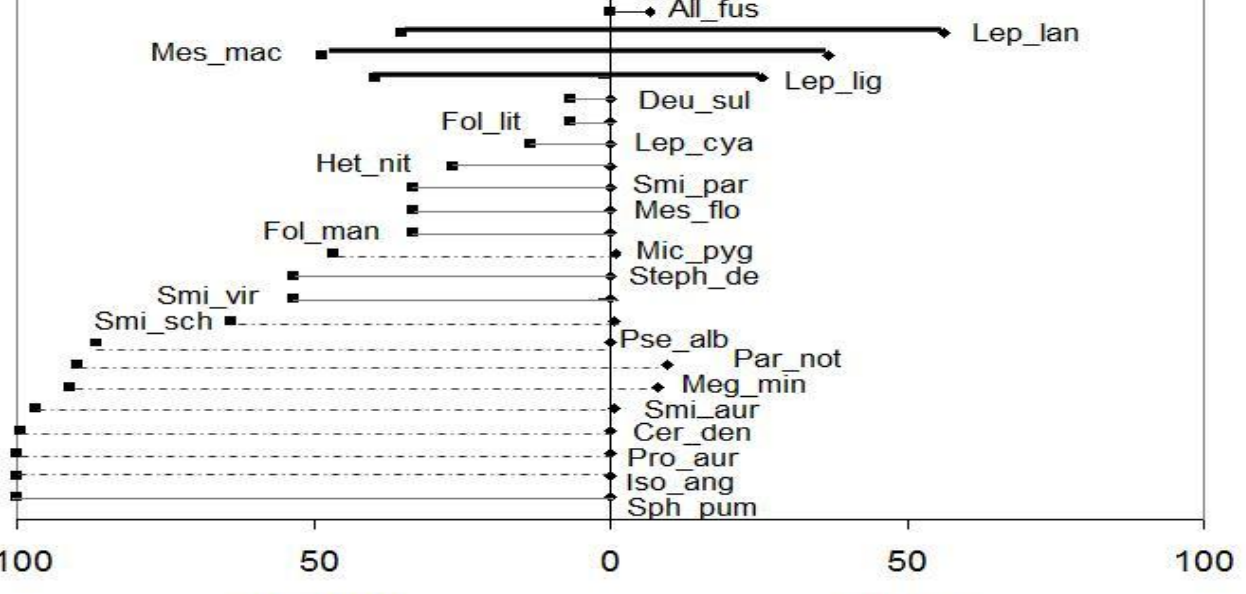

MEADOW

Index value

FOREST

733

$734 \quad$ Figure 2 


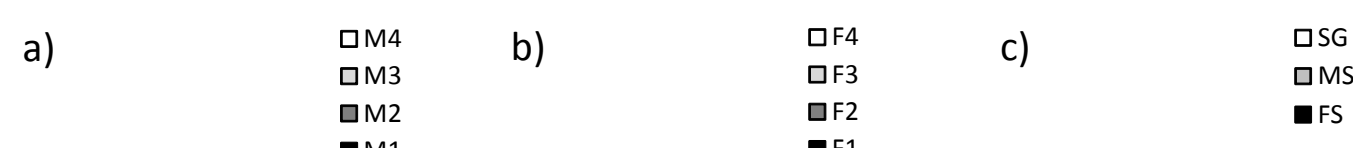
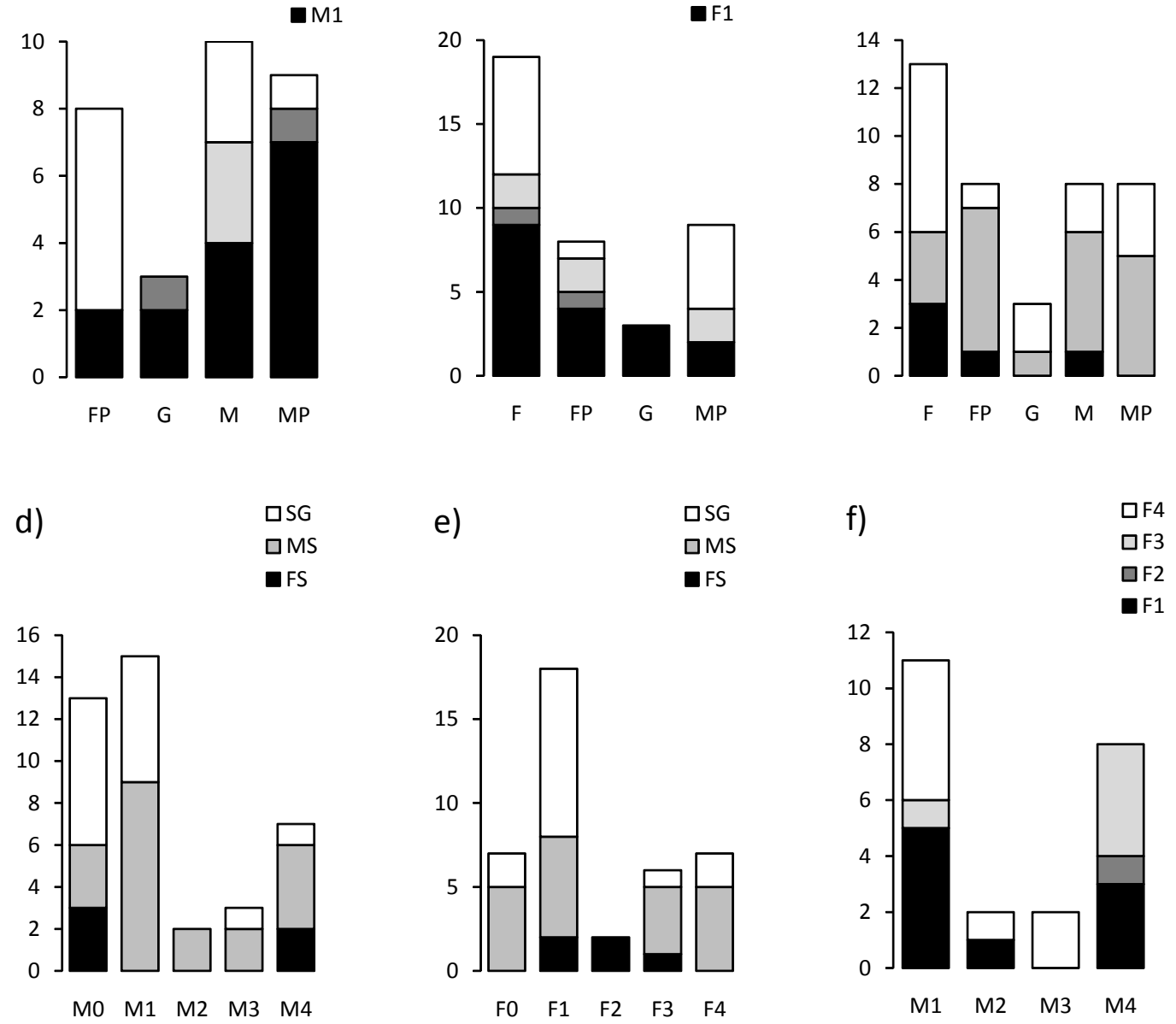

736

737

738

Figure 3

739 